\title{
Antipsychotic long-acting injections: prescribing practice in the UK
}

Thomas R. E. Barnes, Amber Shingleton-Smith and Carol Paton

\section{Background}

Data from the USA, Australia and Europe suggest that the proportion of patients with schizophrenia prescribed an antipsychotic long-acting injection (LAI) varies from around a quarter to a third. Use of LAls has been associated with male gender and younger age.

\section{Aims}

To characterise the use of LAls in people with schizophrenia in three clinical settings in the UK.

\section{Method}

The study used audit data from quality improvement programmes conducted by the Prescribing Observatory for Mental Health.

\section{Results}

Long-acting injections were found to be prescribed for between a quarter and a third of patients, depending on the clinical setting. Flupentixol, risperidone and zuclopenthixol were most commonly prescribed and were combined with an oral antipsychotic in half of cases, frequently constituting high-dose prescribing. The use of LAls was not consistently associated with age, gender or ethnicity.

\section{Conclusions}

Antipsychotic LAls are commonly prescribed. We did not replicate previous findings with respect to demographic variables associated with their use.

\section{Declaration of interest}

Over the past 3 years T.B. has acted as consultant to Servier Johnson \& Johnson and Bristol-Myers Squibb, and C.P. has acted as a consultant to Eli Lilly.
Long-acting injectable formulations of antipsychotic medication are used in the maintenance treatment of schizophrenia and other psychotic illnesses, for the control of symptoms and prevention of relapse. Compared with oral antipsychotics, the psychopharmacological benefits claimed are more consistent bioavailability and more predictable correlations between dosage and plasma drug level, and an improved pharmacokinetic profile allowing lower dosage to be prescribed, with a consequent reduction in side-effect liability. The administration of antipsychotic long-acting injections (LAIs) every few weeks can relieve a patient of the need to remember to take tablets regularly and of the stigma and embarrassment potentially associated with such behaviour; the risk of inadvertent or deliberate overdose is also reduced. Further, if a patient experiences an exacerbation of symptoms or relapse while receiving uninterrupted LAIs, poor medication adherence can be excluded as the cause. A less obvious possible clinical advantage is the necessarily regular contact with the healthcare professional who administers the injection. Aside from the social aspects of such visits for patients who in some cases may be somewhat isolated, they afford the opportunity for review of symptoms and medication side-effects as well as the provision of psychosocial support. However, perhaps the key advantage of injectable antipsychotics is the avoidance of the covert non-adherence possible with oral preparations. ${ }^{1}$ With long-acting medication, any decision by the patient to stop treatment is signalled by failure to attend for, or refusal of, an injection. Thus, healthcare providers are given the opportunity to intervene promptly and provide early and effective follow-up, bearing in mind that non-adherence to the medication regimen can be both a cause and consequence of worsening of illness.

There are provisional data suggesting that the psychopharmacological benefits of LAIs, and the guaranteed medication delivery, may be associated with superior clinical outcomes. For example, in comparison with oral antipsychotics, there are reports of a better global outcome, ${ }^{2}$ a reduced risk of rehospitalisation, ${ }^{3,4}$ and a possible adherence advantage, indicated by a longer time to medication discontinuation. ${ }^{5}$ Further, some patients perceive LAIs as an effective treatment, acting as a guard against relapse and hospitalisation. ${ }^{6}$

The disadvantages of LAI preparations are mainly related to their pharmacokinetics. Titration of the dose against response is necessarily a protracted process, given the time required to reach peak and steady-state plasma levels. ${ }^{1,7}$ Further, any increased risk of relapse consequent upon a reduction in dosage or extension of the injection interval may not be evident for months or even years. The long elimination half-life also means a lack of flexibility should side-effects develop. Another disadvantage is the uncomfortable local reactions occurring at the injection site, characterised by pain, inflammation and induration; ${ }^{8}$ in any one year, around $15-20 \%$ of patients experience such problems. ${ }^{9,10}$ Jones et al suggest that such reactions may be reduced by maximising the interval between injections and using low-volume preparations. ${ }^{10}$ Moreover, clinicians may be concerned that LAIs might compromise their therapeutic relationship with a patient, as the regular administration of injections may be experienced by patients as ignominious and passive, and constrain to some extent their ability to withdraw from treatment. ${ }^{11}$ Clinicians may also perceive such treatment as the cautious choice when faced with cultural, ethnic or communication barriers relating to the need for maintenance antipsychotic treatment. ${ }^{12}$

\section{Use of antipsychotic LAls in clinical practice}

Evidence-based guidelines for the treatment of schizophrenia recommend antipsychotic LAI medication as a treatment option where a patient has expressed a preference for such a formulation, either because of its convenience or as an element of a treatment plan when medication adherence is suboptimal, ${ }^{13}$ where partial (or non-) adherence has led to frequent relapse, ${ }^{14}$ or when avoidance of covert non-adherence is a clinical priority. ${ }^{15}$ 
Discussing choice of medication by detained patients, Roberts et al suggest that where an individual poses a high risk to the public, insistence on reliable acceptance of medication, for example by LAI, can support recovery. ${ }^{16}$ How frequently LAIs are prescribed, however, seems to vary markedly across clinical services, geographical regions and countries, and does not seem to be explained by variation in poor adherence to medication. ${ }^{17}$ Rather, it may reflect factors such as the attitudes of patients and clinicians locally, the profile of the patient population on a range of demographic variables such as age, gender and ethnicity, ${ }^{12,18,19}$ and clinical variables such as forensic history and previous relapse patterns.

\section{How commonly are LAls prescribed?}

Adams et $a l^{2}$ noted that data on the use of antipsychotic LAIs are sparse, but published surveys and audits of antipsychotic prescribing suggest that up to $30 \%$ of people prescribed an antipsychotic may be prescribed an LAI. For example, in 1996 a UK national household survey by Foster et al found that about $29 \%$ of 390 non-hospitalised patients with psychotic disorder were prescribed such medication. ${ }^{20}$ Similarly, in 2003 in our own UK-based audit of 3576 in-patients prescribed an antipsychotic, 1036 (29\%) were receiving a first-generation antipsychotic (FGA) LAI formulation. ${ }^{21}$

A few studies provide information on the relatively recent prevalence of LAI prescription in selected samples from various other countries. For example, a Belgian survey of 1000 ambulatory patients with schizophrenia found that $21.5 \%$ of the total sample were prescribed antipsychotic LAIs. ${ }^{22}$ In a large study conducted over four areas in the Australian Capital Territory, Jablensky et al found that approximately $25 \%$ of patients experiencing a psychotic illness were prescribed such preparations. ${ }^{23}$ An audit of antipsychotic medication prescribed for psychiatric outpatients conducted in Auckland, New Zealand, revealed that out of 3178 individuals, $15 \%$ were prescribed an LAI only and $8 \%$ were receiving both an LAI and an oral antipsychotic. ${ }^{19}$ In Hong Kong $37 \%$ of 267 randomly selected, clinically stable out-patients with a diagnosis of schizophrenia were receiving an LAI. ${ }^{24}$ In the USA a review of continuous prescription records for 400 psychiatric out-patients in the late 1990s revealed that just under a third $(28 \%)$ were prescribed an antipsychotic LAI preparation. ${ }^{18}$ Also in the USA, the Patient Outcome Research Team (PORT) client survey found that half of poorly adherent in-patients and just over a third of poorly adherent out-patients were receiving antipsychotic LAIs. ${ }^{25}$ More recent data derived from a sample of US psychiatrists suggest that less than $30 \%$ of patients with known medication non-adherence are prescribed such preparations. ${ }^{26}$

\section{Prevalence of antipsychotic LAIs in the UK: POMH data}

Data on the frequency of prescription of LAIs are available from three audit-based quality improvement programmes conducted in the UK by the Prescribing Observatory for Mental Health $(\mathrm{POMH})$ (Table 1). This is a national initiative addressing prescribing practice in mental health services; it was set up in 2005 with a tapering grant from the Health Foundation but since 2007 has largely derived its funding from the subscriptions of participating psychiatric services, i.e. UK mental health trusts. The POMH is part of the Royal College of Psychiatrists' Centre for Quality Improvement, and is independent of the pharmaceutical industry. Its work is overseen from a strategic perspective by a central steering group, membership of which includes service users and representatives from partner organisations: Mind, ReThink, the UK Psychiatric Pharmacy Group, the British Association for Psychopharmacology, the Royal College of Nursing and the Royal College of Psychiatrists.

The POMH works with mental health trusts to conduct quality improvement programmes that focus on key aspects of prescribing. Each programme typically starts with a crosssectional audit in a defined patient population. This baseline audit allows actual practice to be measured against evidence-based standards derived from consensus statements and clinical guidelines, such as those produced by the National Institute for Health and Clinical Excellence (NICE). These audit data are collected within the trusts that have chosen to take part, coordinated by each trust's own local POMH project team, and submitted using an online system. Data on age, gender, psychiatric diagnosis and clinical variables relevant to the prescribing practice under scrutiny are also collected for each patient. For each programme, POMH designs and delivers bespoke change interventions that the evidence suggests should lead to improved practice, and these are offered to the trusts in the subsequent year. One year after the baseline audit, another audit is conducted. A further individualised benchmarked report is then produced, which indicates overall change in performance for the national

Table 1 Characteristics of three audit samples of patients prescribed antipsychotic medication: assertive outreach team patients, forensic service patients and acute adult ward in-patients

\begin{tabular}{|c|c|c|c|c|c|c|}
\hline & \multicolumn{2}{|c|}{$\begin{array}{c}\text { AOT patient sample }(n=1616) \\
\text { Antipsychotic LAl }\end{array}$} & \multicolumn{2}{|c|}{$\begin{array}{l}\text { Forensic patient sample }(n=1502) \\
\text { Antipsychotic LAI }\end{array}$} & \multicolumn{2}{|c|}{$\begin{array}{c}\text { Acute in-patient sample }(n=2032) \\
\text { Antipsychotic LAI }\end{array}$} \\
\hline & $\begin{array}{c}\text { Prescribed } \\
n=583(36 \%)\end{array}$ & $\begin{array}{l}\text { Not prescribed } \\
n=1033(64 \%)\end{array}$ & $\begin{array}{c}\text { Prescribed } \\
n=419(28 \%)\end{array}$ & $\begin{array}{l}\text { Not prescribed } \\
n=1083(72 \%)\end{array}$ & $\begin{array}{c}\text { Prescribed } \\
n=713(35 \%)\end{array}$ & $\begin{array}{l}\text { Not prescribed } \\
n=1319(65 \%)\end{array}$ \\
\hline Age, years: median (range) & $40(18-76)$ & $38(16-73)$ & $38(18-71)$ & $37(18-71)$ & $40(18-71)$ & $37(17-71)$ \\
\hline Male, \% & 68 & 75 & 87 & 89 & 65 & 64 \\
\hline \multicolumn{7}{|l|}{ Self-assigned ethnicity, \% } \\
\hline White British/rish & 66 & 68 & 54 & 62 & 63 & 63 \\
\hline Black/Black British & 18 & 14 & 33 & 22 & 19 & 17 \\
\hline Asian/Asian British & 6 & 7 & 5 & 6 & 5 & 7 \\
\hline Chinese & 1 & $<1$ & 0 & 1 & $<1$ & 1 \\
\hline Mixed & 3 & 3 & 4 & 4 & 5 & 4 \\
\hline Other ethnic group & 2 & 4 & 2 & 4 & 4 & 4 \\
\hline Not stated/not available & 4 & 4 & 2 & 1 & 4 & 5 \\
\hline $\begin{array}{l}\text { Prescribed an anti-Parkinsonian/ } \\
\text { anticholinergic agent, \% }\end{array}$ & 30 & 19 & 61 & 36 & \multicolumn{2}{|c|}{ Information not collected } \\
\hline
\end{tabular}


sample of trust services as well as change for each individual trust and its participating clinical teams. Trusts are encouraged to feed the findings into their local clinical effectiveness programme and to use them as evidence of good practice. Further information regarding $\mathrm{POMH}$ methodology is available in papers reporting on particular quality improvement programmes. ${ }^{27-29}$

The first $\mathrm{POMH}$ programme to be considered here addressed high-dose and combined antipsychotic prescribing; 32 mental health trusts submitted baseline data for 3492 patients from 218 acute adult psychiatric wards. ${ }^{27}$ Of the 2032 (58\%) patients with a diagnosis of schizophrenia or related disorder (ICD-10 codes F20-29), 713 (35\%) were prescribed an antipsychotic LAI (Table 1). ${ }^{30}$

The second programme addressed screening for metabolic syndrome in community-living patients prescribed antipsychotic medication. ${ }^{28,29}$ In the baseline audit, 48 assertive outreach teams across the UK submitted data on screening for the four aspects of metabolic syndrome (blood pressure, obesity, blood glucose and plasma lipids) over the previous year for 1966 patients. The information collected on the 1616 (82\%) patients with a diagnosis of schizophrenia or related disorder revealed that over a third $(36 \%)$ were prescribed an antipsychotic LAI.

The third programme gathered information on high-dose and combined antipsychotic prescribing in forensic services in 21 participating National Health Service (NHS) trusts; ${ }^{27}$ for the baseline audit, data were submitted for 1891 patients from 155 forensic wards. Among the 1502 (79\%) patients with a diagnosis of schizophrenia or related disorder, over a quarter (28\%) were prescribed an antipsychotic LAI.

In relation to the second and third programmes, conducted in community and forensic settings, the care provided is for patients who are at high-risk for non-adherence to oral antipsychotic medication and in whom avoidance of covert non-adherence is a clinical priority. Assertive outreach teams provide high-intensity care to out-patients who have a history of non-engagement with services, repeated admissions to hospital and chaotic lifestyles that may include contact with the police; in a survey of London assertive outreach teams, $35 \%$ of patients had been violent in the previous 2 years and, over a 9-month follow-up period, a quarter had been admitted to hospital under compulsion. ${ }^{31}$ Forensic in-patient services provide care for patients who are considered to pose a high risk to others; the majority of such patients have committed serious offences, usually of a violent nature. Almost all of these people are detained under the Mental Health Act and are commonly subject to restriction orders. ${ }^{32}$
It is possible that the relatively high prevalence of use of LAIs in the three POMH clinical populations is influenced by the specific characteristics of these populations, and that LAIs are used somewhat less frequently in general psychiatric out-patient populations.

\section{Frequency and dosage of LAI prescriptions}

A large, 3-year prospective study by Shi et al examined data from the US Schizophrenia Care and Assessment Program relating to the dosage and frequency of antipsychotic LAIs in clinical practice. ${ }^{33}$ Of 2186 study participants, about a quarter (26\%) were prescribed a first-generation antipsychotic (FGA) LAI at least once during the study period, whereas almost three-quarters (74\%) were prescribed only oral antipsychotics. In this study the modal doses of the two most commonly administered LAIs, fluphenazine $(n=273)$ and haloperidol ( $n=234)$, were $25 \mathrm{mg}$ every 2 weeks and $100 \mathrm{mg}$ every 4 weeks respectively. In a sample of 261 patients prescribed antipsychotic LAIs in Australia, ${ }^{34}$ the vast majority of whom had a diagnosis of schizophrenia or schizoaffective disorder, more than half (57\%) were prescribed zuclopenthixol, followed by flupentixol, fluphenazine and haloperidol. The modal injection interval for all preparations was 2-weekly, except haloperidol, for which it was 4-weekly. In the New Zealand audit by Humberstone et al, flupentixol LAI was the most commonly prescribed (40\%) and zuclopenthixol the least commonly prescribed $(4 \%){ }^{19}$

In our UK-based audit $43 \%$ of prescriptions for antipsychotic LAIs were for flupentixol and $29 \%$ for zuclopenthixol. ${ }^{21}$ Just over a quarter $(26 \%)$ of all the preparations were for weekly administration and 57\% were 2-weekly. Zuclopenthixol was twice as likely as other antipsychotics to be prescribed weekly.

\section{Frequency and dosage: POMH data}

Based on the 1715 patients reported in the three POMH audits to be prescribed an LAI, the most commonly prescribed preparations were flupentixol, risperidone and zuclopenthixol; overall, these three preparations accounted for just over three-quarters of all LAI prescriptions. Injection frequency and the doses used are shown in Table 2. For all three preparations the median frequency of administration was 2-weekly, but the distribution of injection interval times differed across the preparations, with the modal frequency for zuclopenthixol being weekly in the forensic sample. These data indicate that the injection interval for LAIs tends to

\section{Table 2 Frequency of administration and dosage of commonly used long-acting injections in three clinical settings ${ }^{a}$}

\begin{tabular}{|c|c|c|c|c|c|c|}
\hline \multirow[b]{2}{*}{$\begin{array}{l}\text { Most frequently prescribed } \\
\text { LAls in each setting }\end{array}$} & \multirow[b]{2}{*}{$\begin{array}{l}\text { Median frequency } \\
\text { of administration, } \\
\text { weeks (range) }\end{array}$} & \multirow[b]{2}{*}{$\begin{array}{l}\text { Median dosage, } \\
\text { mg/week (range) }\end{array}$} & \multicolumn{2}{|c|}{ Mean percentage of BNF maximum dose } & \multicolumn{2}{|c|}{ Percentage anticholinergic use } \\
\hline & & & $\begin{array}{c}\text { LAI } \\
\text { monotherapy } \\
\%\end{array}$ & $\begin{array}{c}\text { Combination } \\
\text { with another } \\
\text { antipsychotic, \% }\end{array}$ & $\begin{array}{c}\text { LAl } \\
\text { monotherapy } \\
\%\end{array}$ & $\begin{array}{c}\text { Combination } \\
\text { with another } \\
\text { antipsychotic, \% }\end{array}$ \\
\hline \multicolumn{7}{|l|}{ AOT community patients } \\
\hline Flupentixol decanoate & & & & & 26 & 14 \\
\hline Risperidone & & & & & 10 & 4 \\
\hline Zuclopenthixol decanoate & & & & & 29 & 6 \\
\hline \multicolumn{7}{|l|}{ Forensic services patients } \\
\hline Flupentixol decanoate & $2(1-4)$ & $75(10-600)$ & 29 & 122 & 36 & 33 \\
\hline Risperidone & $2(2)$ & $25(12.5-50)$ & 88 & 183 & 16 & 29 \\
\hline Zuclopenthixol decanoate & $2(1-4)$ & $300(37.5-900)$ & 50 & 183 & 26 & 40 \\
\hline \multicolumn{7}{|l|}{ Acute adult in-patients } \\
\hline Flupentixol decanoate & $2(1-4)$ & $50(5-600)$ & 15 & 103 & & \\
\hline Risperidone & $2(1-4)$ & $19(6.25-37.5)$ & 85 & 162 & & \\
\hline Zuclopenthixol decanoate & $2(1-6)$ & $200(10-900)$ & 47 & 137 & & \\
\hline
\end{tabular}


be at the shorter end of the recommended range for each preparation. The reasons for such a strategy are unclear but may include maximising the dose that is administered and providing a structure for increased patient contact. However, more frequent administration is likely to increase the risk of injection site reactions. There were also differences between the preparations with respect to the doses prescribed. Risperidone was more likely to be prescribed at doses towards the top of the licensed dosage range than were zuclopenthixol or flupentixol. This may at least partially reflect the fact that the licensed dosage range for risperidone is narrower than the respective ranges for zuclopenthixol and flupentixol.

\section{Combination with oral antipsychotics}

Licensing studies that support the efficacy and tolerability of antipsychotic medication generally test a single antipsychotic against placebo, in patients who are matched for other important factors that are known to influence outcome. In clinical practice, however, antipsychotic combinations are commonly used (e.g. Paton et al, 2008). ${ }^{27}$ With respect to combinations that include an LAI preparation, Shi et al in a US study found that two-thirds of those receiving LAIs were prescribed oral supplementation for an average of 6 months in the first year after enrolment. ${ }^{33}$ Despite the combination of an oral and an LAI antipsychotic being consistently associated with higher doses 'in excess of best practice guidelines, ${ }^{19}$ the prescription of such a combination seems to be a common practice. For example, in an Australian sample of 105 forensic patients receiving LAIs, two-thirds were also prescribed an oral antipsychotic. ${ }^{35}$

\section{Combination with oral antipsychotics: POMH data}

Figure 1 shows the proportions of the patients with a reported clinical diagnosis within ICD-10 category F20-29 (schizophrenia, schizotypal and delusional disorders) in the three audits prescribed an LAI either as monotherapy or in combination with an oral antipsychotic, and the relationship with high-dose prescribing; high dose was calculated by the percentage method. ${ }^{36}$ Across the three samples, for patients with an F20-29 diagnosis prescribed one of the three most commonly used LAIs (flupentixol,

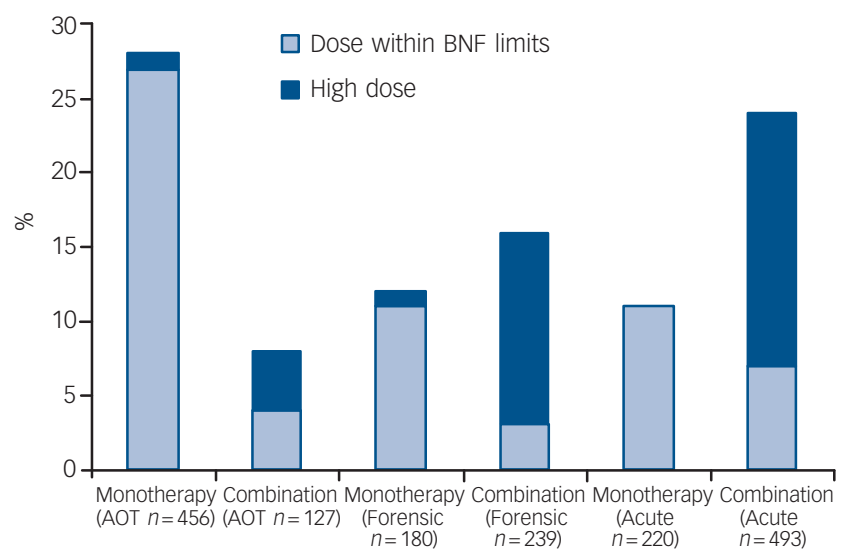

Fig. 1 Proportion of patients with schizophrenia-spectrum disorders from the three audit samples (acute in-patients assertive outreach team patients and forensic service patients) receiving antipsychotic long-acting injections as monotherapy or in combination with an oral antipsychotic, and the relationship with high dose (AOT, assertive outreach team; BNF, British National Formulary). risperidone and zuclopenthixol), the proportion also prescribed an oral antipsychotic was approximately half - of the same order as the prescription of oral combinations in these samples. Note that these dosage data relate to prescribing practice, and thus where the additional oral medication was a pro re nata (p.r.n. or 'as required') prescription, it may or may not have been administered.

These data show that combining the prescription of an oral antipsychotic with an LAI was more common on acute in-patient wards and in forensic services than in assertive outreach team patients, and more likely to be a marker of high dosage (Fig. 1). In the acute in-patient sample, this may partly reflect the use of additional oral medication to control behavioural disturbance associated with relapse (see Paton et al, 2008). ${ }^{27}$ In the forensic sample, the relatively high level of combined oral and LAI preparations, and the resultant high dosage prescribed, may partly account for the greater requirement for anticholinergic and antiParkinsonian medication in patients prescribed LAIs (Table 1). In both samples risperidone LAI, when used as antipsychotic monotherapy, was associated with lower rates of anticholinergic prescribing than flupentixol and zuclopenthixol (Table 2). This apparent advantage seems to be at least partly lost when risperidone is prescribed in combination with another antipsychotic.

\section{Characteristics of patients prescribed LAls}

The study by Shi et al also examined the characteristics of patients selected for LAIs. ${ }^{33}$ Compared with those prescribed oral antipsychotics, patients receiving FGA-LAIs were more likely to be younger, male, African American and to have been arrested. This is in line with several earlier USA studies finding that 'nonCaucasian' patients were more likely to have been prescribed a FGA-LAI than oral medication. ${ }^{18}$ Further, Shi et al reported that patients prescribed LAIs had more severe psychotic symptoms and disorganised thinking, and were more likely to use alcohol and illicit substances and to have been previously admitted to hospital. ${ }^{33}$ In the Hong Kong study of out-patients with schizophrenia by Xiang et al already mentioned, those receiving an LAI were characterised as being older with more past hospitalisations, more likely to be prescribed combined antipsychotics and anticholinergic agents and more likely to be on 'conditional discharge' than those prescribed oral antipsychotics. ${ }^{24}$ They were also more likely to have a history of suicide attempts, but notably not of violence.

Some of the same characteristics emerged from a UK crosssectional survey of a small sample of patients with schizophrenia with stable disorder living in the community. ${ }^{37}$ The patients prescribed LAIs were predominantly men, tended to live alone, were more likely to have been admitted to hospital under the Mental Health Act and had lower levels of insight than those prescribed oral antipsychotics. They were also receiving significantly higher doses of antipsychotic medication. From our POMH audit data, only limited information is available on the characteristics of patients prescribed LAIs (see Table 1). There was no age or gender difference between those prescribed LAIs and those prescribed only oral antipsychotics in either the assertive outreach or forensic samples.

\section{Conclusion}

Long-acting antipsychotic injections are commonly prescribed, with the available data from the USA, Australia and Europe suggesting that in at least some centres between a quarter and a 
third of patients with schizophrenia receive such medication. The POMH data suggest that flupentixol, risperidone and zuclopenthixol are the most commonly prescribed LAIs in clinical services in the UK, and that these preparations are associated with different prescribing patterns; zuclopenthixol being more often prescribed for weekly administration, and risperidone more often prescribed at doses towards the top of its relatively narrow licensed dosage range.

The POMH data suggest that approximately a third of patients prescribed an LAI are prescribed an anticholinergic drug as well, the prevalence of such prescribing being somewhat lower in patients prescribed risperidone LAI as antipsychotic monotherapy than in those prescribed flupentixol or zuclopenthixol. The data also show that patients prescribed LAIs in acute in-patient and forensic service settings are more likely to be prescribed additional oral antipsychotic medication, and are consequently at greater risk of receiving a higher daily dosage than patients in the community. The proportion of patients prescribed an LAI and additional oral antipsychotic medication was similar across the three most commonly used preparations, and the combination had led to high antipsychotic dosage in over half of those for whom it was prescribed. Such prescribing practice has implications for the relevance of efficacy and tolerability data derived from randomised controlled trials of LAI monotherapy in standard dosage, in everyday clinical practice.

Some clinical studies have found demographic variables such as male gender and younger age, and clinical variables such as more severe psychotic symptoms and a history of contact with the criminal justice system, to be associated with the use of LAIs. These findings with respect to demographic variables were not replicated in the POMH samples.

\section{Acknowledgements}

We thank the central Prescribing Observatory for Mental Health (POMH) staff and the loca POMH teams within all the participating mental health trusts as well as the clinicians and staff involved in data collection.

Thomas R. E. Barnes, MD, FRCPsych, DSC, Department of Psychological Medicine Imperial College London; Amber Shingleton-Smith, MA, Royal College of Psychiatrists' Centre for Quality Improvement, London; Carol Paton, BSC, Psychiatrists' Centre for Quality Improvement, London; Carol Paton, BSC,
DipclinPharm, MRPharmS, MCMHP, Division of Psychological Medicine, Imperial College, London, UK

Correspondence: Carol Paton, Division of Psychological Medicine, Imperial College, Charing Cross Campus, Reynold's Building, St Dunstan's Road, London W6 8RP, UK. Email: Carol.Paton@oxleas.nhs.uk

\section{References}

1 Barnes TRE, Curson DA. Long-acting depot antipsychotics: a risk-benefit assessment. Drug Saf 1994; 10: 464-79.

2 Adams CE, Fenton MKP, Quraishi S, David AS. Systematic meta-review of depot antipsychotic drugs for people with schizophrenia. Br J Psychiatry 2001; 179: 290-9.

3 Schooler NR. Relapse and rehospitalisation: comparing oral and depot antipsychotics. J Clin Psychiatry 2003; 64 (suppl 16): 14-7.

4 Tiihonen J, Wahlbeck K, Lonnqvist J, Klaukka T, Ioannidis JPA, Volavka J, et al Effectiveness of antipsychotic treatments in a nationwide cohort of patients in community care after first hospitalization due to schizophrenia and schizoaffective disorder: observational follow-up study. BMJ 2006; 333: 224.

5 Zhu B, Ascher-Svanum H, Shi LB, Faries D, Montgomery W, Marder SR. Time to discontinuation of depot and oral first-generation antipsychotics in the usual care of schizophrenia. Psychiatr Serv 2008; 59: 315-17.

6 Svedberg B, Backenroth-Ohsako G, Lützén $\mathrm{K}$. On the path to recovery: patients' experiences of treatment with long-acting injections of antipsychotic medication. Int J Ment Health Nurs 2003; 12: 110-8.

7 Kane JM, Aguglia E, Altamura AC, Ayuso Gutierrez JL, Brunello N, Fleischhacker WW, et al. Guidelines for depot antipsychotic treatment in schizophrenia. European Neuropsychopharmacology Consensus Conference in Siena, Italy. Eur Neuropsychopharmacol 1998; 8: 55-66.

8 Bloch Y, Mendlovic S, Strupinsky S, Altshuler A, Fennig S, Ratzoni G. Injections of depot antipsychotic medications in patients suffering from schizophrenia: do they hurt? J Clin Psychiatry 2001; 62: 855-9.

9 Hay J. Complications at site of injection of depot neuroleptics. BMJ 1995; 311: 421.

10 Jones JC, Day JC, Taylor JR, Thomas CS. Investigation of depot neuroleptic injection site reactions. Psychiatr Bull 1998; 22: 605-7.

11 Barnes TRE. Why indeed? Invited commentary on: Why aren't depot antipsychotics prescribed more often and what can be done about it? Advan Psychiatr Treat 2005; 11: 211-3.

12 Ziguras S, Lambert TJR, McKenzie DP, Pennella J. The influence of client's ethnicity on psychotropic medication management in community mental health services. Aust N Z J Psychiatry 1999; 33: 882-8.

13 Moore TA, Buchanan RW, Buckley PF, Chiles JA, Conley RR, Crismon ML, et al. The Texas Medication Algorithm Project antipsychotic algorithm for schizophrenia: 2006 update. J Clin Psychiatry 2007; 68; 1751-62.

14 Lehman AF, Lieberman JA, Dixon LB, McGlashan TH, Miller AL, Perkins DO, et al. Practice guideline for the treatment of patients with schizophrenia, 2nd edition. Am J Psychiatry 2004; 161 (suppl): 1-56.

15 National Institute for Health and Clinical Excellence. Schizophrenia: Core Interventions in the Treatment and Management of Schizophrenia in Adults in Primary and Secondary Care (Update). National Clinical Practice Guideline 82. NICE, 2009 (http://www.nice.org.uk/nicemedia/pdf/ CG82FullGuideline.pdf).

16 Roberts G, Dorkins E, Wooldridge J, Hewis E. Detained - what's my choice? Part 1: Discussion. Advan Psychiatr Treat 2008; 14: 172-80.

17 Dencker $\mathrm{S}$, Axelsson R. Optimising the use of depot antipsychotics. CNS Drugs 1996; 6: 367-81

18 Covell NH, Jackson CT, Evans AC, Essock SM. Antipsychotic prescribing practices in Connecticut's public mental health system: rates of changing medications and prescribing styles. Schizophr Bull 2002; 28: 17-29.

19 Humberstone V, Wheeler A, Lambert T. An audit of outpatient antipsychotic usage in the three health sectors of Auckland, New Zealand. Aust N Z J Psychiatry 2004; 38: 240-5.

20 Foster $\mathrm{K}$, Meltzer $\mathrm{H}$, Gill B. Adults with a psychotic disorder living in the community. OPCS Surveys of Psychiatric Morbidity in Great Britain, Report 8. TSO (The Stationery Office), 1996.

21 Paton C, Lelliott $P$, Harrington M, Okocha C, Sensky T, Duffett R. Patterns of antipsychotic and anticholinergic prescribing for hospital inpatients. $J$ Psychopharmacol 2003; 17: 223-9.

22 Hanssens L, De Hert M, Wampers M, Reginster JY, Peuskens J. Pharmacological treatment of ambulatory schizophrenic patients in Belgium. Clin Pract Epidemiol Ment Health 2006; 2: 11.

23 Jablensky A, McGrath J, Herrman $\mathrm{H}$, Castle D, Gureje O, Evans $\mathrm{M}$, et al. Psychotic disorders in urban areas: an overview of the study on low prevalence disorders. Aust N Z J Psychiatry 2000; 34: 221-36.

24 Xiang $\mathrm{YT}$, Weng $\mathrm{YZ}$, Leung $\mathrm{CM}$, Tang WK, Ungvari GS. Clinical and social determinants of use of depot antipsychotics for patients with schizophrenia in Hong Kong. Hong Kong J Psychiatry 2006; 16: 71-5.

25 Lehman AF, Steinwachs DM. Patterns of usual care for schizophrenia: initial results from the Schizophrenia Patient Outcomes Research Team (PORT) Client Survey. Schizophr Bull 1998; 24: 11-20.

26 West JC, Marcus SC, Wilk J, Countis LM, Regier DA, Olfson M. Use of depot antipsychotic medications for medication nonadherence in schizophrenia. Schizophr Bull 2008; 34: 995-1001.

27 Paton C, Barnes TRE, Cavanagh MR, Taylor D, Lelliott P, POMH-UK Project Team. High-dose and combination antipsychotic prescribing in acute adult wards in the UK: the challenges posed by p.r.n. prescribing. $\mathrm{Br} J$ Psychiatry 2008; 192: 435-9.

28 Barnes TRE, Paton C, Cavanagh MR, Hancock E, Taylor DM, UK Prescribing Observatory for Mental Health. A UK audit of screening for the metabolic side effects of antipsychotics in community patients. Schizophr Bull 2007; 33 1397-401.

29 Barnes TRE, Paton C, Hancock E, Cavanagh MR, Taylor D, Lelliott $P$, et al. Screening for the metabolic syndrome in community psychiatric patients prescribed antipsychotics: a quality improvement programme. Acta Psychiatr Scand 2008; 118: 26-33.

30 World Health Organization. The ICD-10 Classification of Mental and Behavioural Disroders. Clinical Description and Diagnostic Guidelines. WHO, 1992.

31 Priebe S, Fakhoury W, Watts J, Bebbington P, Burns $T$, Johnson S, et al. Assertive outreach teams in London: patient characteristics and outcomes. 
Pan-London Assertive Outreach Study, Part 3. Br J Psychiatry 2003; 183: 148-54.

32 Anderson J. The interface with forensic services. In Psychiatric Intensive Care (2nd edn) (eds MD Beer, S Pereira, C Paton): 191-201. Cambridge University Press, 2008

33 Shi L, Ascher-Svanum H, Zhu B, Faries D, Montgomery W, Marder SR. Characteristics and use patterns of patients taking first-generation depot antipsychotics or oral antipsychotics for schizophrenia. Psychiatr Serv 2007; 58: $482-8$.

34 Herriot $P$, Kheirani K. Survey of depot antipsychotic prescribing in southern Adelaide. Australas Psychiatry 2005; 13: 253-7.
35 Bains JJS, Nielssen OB. Combined depot antipsychotic medications with novel antipsychotics in forensic patients: a practice in search of a principle. Psychiatr Bull 2003; 27: 14-6.

36 Royal College of Psychiatrists. Consensus Statement on High-Dose Antipsychotic Medication. (Council Report CR138). Royal College of Psychiatrists, 2006.

37 Mahadun PN, Marshall M. Insight and treatment attitude in schizophrenia: comparison of patients on depot and atypical antipsychotics. Psychiatr Bull 2008; 32: 53-6. 